\title{
Boron Compounds as Additives for the Cationic Polymerization using Coumarin Derivatives in Epoxy-silicones
}

\author{
Mira Abdallah ${ }^{1,2,3}$, Akram Hijazi $^{3}$, Pier Giorgio Cozzi*4 ${ }^{4}$ Andrea Gualandi ${ }^{4}$, Frederic Dumur*5, \\ Jacques Lalevée* ${ }^{1,2}$ \\ ${ }^{1}$ Université de Haute-Alsace, CNRS, IS2M UMR 7361, F-68100 Mulhouse, France \\ ${ }^{2}$ Université de Strasbourg, France \\ ${ }^{3}$ EDST, Université Libanaise, Campus Hariri, Hadath, Beyrouth, Liban \\ ${ }^{4}$ ALMA MATER STUDIORUM Università di Bologna, Dipartimento di Chimica "G. \\ Ciamician", Via Selmi2, 40126 Bologna, Italy \\ ${ }^{5}$ Aix Marseille Univ, CNRS, ICR UMR 7273, F-13397 Marseille, France
}

Corresponding author: jacques.lalevee@uha.fr

\begin{abstract}
The idea of this article target to use borane: $\mathrm{B}\left(\mathrm{C}_{6} \mathrm{~F}_{5}\right)_{3}$ and borate: $\mathrm{C}_{32} \mathrm{H}_{12} \mathrm{BF}_{24} \mathrm{Na}$ as additives for the cationic polymerization of epoxy-silicones under visible light, in the presence of coumarin derivatives as photosensitizers and 4-isopropyl-4'-methyldiphenyliodonium tetrakis(pentafluorophenyl)borate (SC939). The effect of boron compounds on the absorption and the emission spectra of a coumarin is particularly outlined. These boranes and borates improve both the polymerization rate and the final conversion of the system. Moreover, the effect of adding water on the reactivity of the examined systems has been studied. In an interesting way, these compounds showed that they were able to enhance the polymerization rate without light which is known as “'Dark Polymerization', This latter behavior is highly desired for practical applications. Furthermore, the cationic polymerization of (3,4-epoxycyclohexane)methyl 3,4-
\end{abstract}


epoxycyclohexylcarboxylate (EPOX) in the presence of Coumarin/Borane (or Borate)/SC938 (bis(4-tert-butylphenyl)iodonium hexafluorophosphate) is also studied using LED at $405 \mathrm{~nm}$. Finally, the very high photoreactivity of boron compounds was also shown for the development of new cationic 3D printing resins upon exposure to a LED projector at $405 \mathrm{~nm}$ as well as for laser writing experiments by means of a laser diode at $405 \mathrm{~nm}$. 3D printing experiments which occur through a cationic process can be useful to reduce the shrinkage usually observed in radical polymerization.

KEYWORDS: Boron Compounds; Borane; Borate; Cationic polymerization; Co-initiator; Coumarin; Dark Polymerization.

\section{INTRODUCTION}

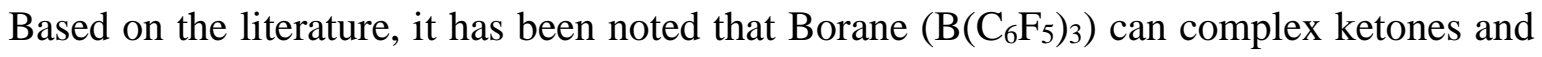
therefore can change their absorption or emission properties and then their photochemical reactivity [1]. However, the reactivity of the complex formed has not been tested for cationic polymerization processes. On the other hand, the controlled cationic polymerization of $p$ methoxystyrene in the presence of $\mathrm{B}\left(\mathrm{C}_{6} \mathrm{~F}_{5}\right)_{3}$ in $\mathrm{CH}_{2} \mathrm{Cl}_{2} / \mathrm{CH}_{3} \mathrm{CN}$ mixtures at $20^{\circ} \mathrm{C}$ has been reported in [2] without any light activation. In this latter paper, it has been mentioned that $\mathrm{B}\left(\mathrm{C}_{6} \mathrm{~F}_{5}\right)_{3}$ can react with water to create an acid in the form of a complex which can initiate the cationic polymerization of styrene.

In this work, we want to combine coumarin with boron compounds (noted B; Borane: $\mathrm{B}\left(\mathrm{C}_{6} \mathrm{~F}_{5}\right)_{3}$ or Borate: $\left.\mathrm{C}_{32} \mathrm{H}_{12} \mathrm{BF}_{24} \mathrm{Na}\right)$ where a complex can be formed [1]. Actually, the formed complex can considerably affect the fluorescence but only slightly the absorption spectra of 
coumarin. Moreover, the novelty of our work consists in studying the influence of the formed [Coum-B] complex on the reactivity of the photopolymerization processes in the presence of iodonium salt upon irradiation with the LED at $405 \mathrm{~nm}$. A big effect was observed in the presence of boron compounds where very high rates of polymerization and also final reactive function conversions were achieved for the CP of epoxy-silicones. Indeed, tack-free polymers are obtained in the presence of the boron compounds. The structures of the coumarins and the boron compounds used in this study are illustrated in Scheme 1.

The impact of boron compounds on the polymerization of EPOX was also shown in the presence of SC938 under visible light irradiation (LED at $405 \mathrm{~nm}$ ). Besides, the addition of water to the systems will be also discussed below. The photoinitiating abilities and also the photochemical mechanisms of the investigated systems were also examined.

Otherwise, one of the problems which are usually observed in photochemistry is that if we cut the irradiation, the polymerization stops. So, in order to access to the shadow areas, it is interesting to have dark polymerization where the polymerization can continue even when the irradiation is turned off. For this reason, the dark polymerization was studied in the presence of boron compounds and this showed that the polymerization can continue without light.

On the other hand, several fields are interested in the use of 3D printing technologies starting from biomedical engineering [3] to radiology [4] and 3D food printing [5] and so on. Actually, in 3D printing, the cationic monomers associated with a ring-opening polymerization are characterized by lower shrinkage compared to the radical monomers (meth(acrylates)), hence the importance of developing new cationic photosensitive systems is highly desired. 
Therefore, due to the outstanding reactivity of the novel investigated systems in the presence of boron compounds, new photocurable cationic formulations are proposed here for LED projector (@ $405 \mathrm{~nm}$ ) 3D printing but also for laser writing experiments upon laser diode at $405 \mathrm{~nm}$.
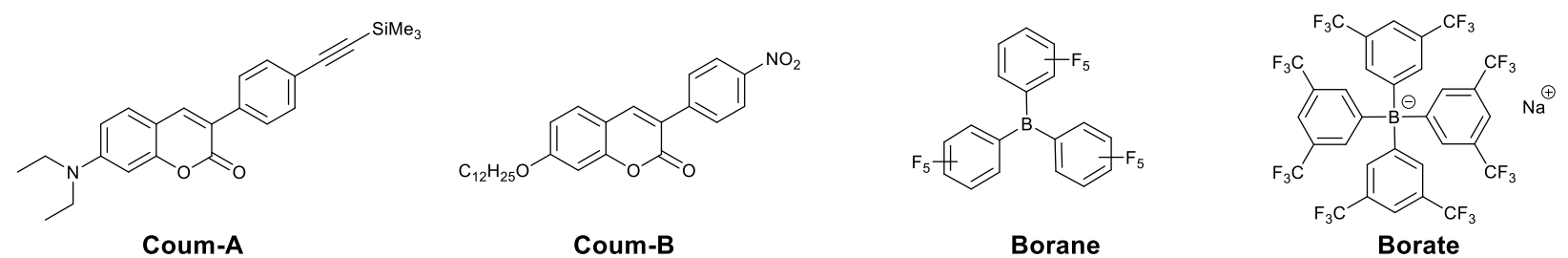

Scheme 1. Chemical Structures of the Coumarins (synthesized) and the Boron Compounds used in this Study.

\section{EXPERIMENTAL PART}

\subsection{Other Commercial Chemical Compounds}

All commercial chemical compounds were selected with highest purity available and used as received, they are represented in Scheme 2. Di-tert-butyl-diphenyl iodonium hexafluorophosphate (SpeedCure 938) and 4-isopropyl-4'-methyldiphenyliodonium tetrakis(pentafluorophenyl)borate (SC939) were obtained from Lambson Ltd. (3,4Epoxycyclohexane)methyl 3,4-epoxycyclohexylcarboxylate (EPOX; Uvacure 1500) was obtained from Allnex. (Epoxycyclohexylethyl) methylsiloxane-dimethylsiloxane copolymer (Silcolease UV POLY 200: Epoxy-silicone) was obtained from Bluestar Silicones - France. EPOX and Epoxysilicone were selected as benchmarked resins for cationic polymerization.

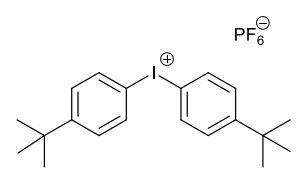

SpeedCure 938

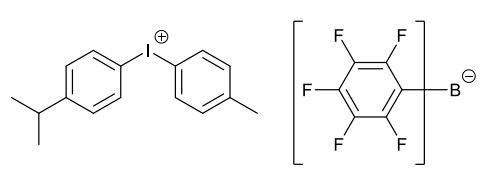

SpeedCure 939

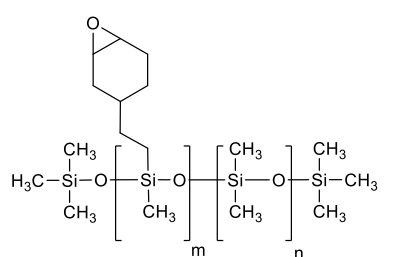

EPOX-Si200

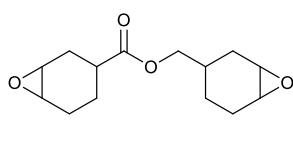

EPOX 
Scheme 2. Chemical structures of the commercial compounds used in this work.

\subsection{Light Irradiation Sources}

The Light Emitting Diode (LED) @405nm $\left(\mathrm{I}_{0}=110 \mathrm{~mW} . \mathrm{cm}^{-2}\right)$ has been used as the visible light source of irradiation for the photopolymerization processes. Besides, a LED projector at 405 $\mathrm{nm}\left(\mathrm{I}_{0}=100-130 \mathrm{~mW} \cdot \mathrm{cm}^{-2}\right)$ and a laser diode (@ $\left.405 \mathrm{~nm}\right)$ were used for 3D printing experiments.

\subsection{Cationic Photopolymerization (CP) followed by Real-Time (RT)-FTIR}

In this research, the cationic polymerization of epoxy-silicones or EPOX was carried out in the presence of different two-component photoinitiating systems (PISs) based on Coum-a/SC939 $(0.05 \% / 1 \% \mathrm{w} / \mathrm{w})$ couples for the $\mathrm{CP}$ of epoxy-silicones and Coum-b/SC938 $(0.5 \% / 1 \% \mathrm{w} / \mathrm{w})$ couples for the $\mathrm{CP}$ of EPOX. In addition, three-component systems based on Couma/SC939/Borane (or Borate) $(0.05 \% / 1 \% / 0.5 \%$ or $1 \%$ or $2 \% \mathrm{w} / \mathrm{w})$ combinations for the $\mathrm{CP}$ of epoxy-silicones and Coum-b/SC938/Borane (or Borate) $(0.5 \% / 1 \% / 0.5 \% \mathrm{w} / \mathrm{w})$ combinations for the CP of EPOX, have been also tested. The weight percent of the different chemical compounds has been calculated according to the monomer content (w/w). The CP of epoxy-silicones or EPOX is realized under air on $\mathrm{a} \mathrm{BaF}_{2}$ pellet on which the photosensitive formulation is put (thickness $\sim 25$ $\mu \mathrm{m})$. For thin samples, the evolution of the epoxy group content of epoxy-silicones and EPOX was continuously followed by real time FTIR spectroscopy (JASCO FTIR 4100) at about $3000 \mathrm{~cm}^{-1}$ and $790 \mathrm{~cm}^{-1}$, respectively. The procedure used to monitor the photopolymerization profiles has been already described in detail in [6-8].

\subsection{UV-visible Absorption Experiments}

The study of the UV-visible absorption properties of the different compounds used in this work was performed using a JASCO V730 UV-visible spectrometer. 


\subsection{Fluorescence Experiments}

The fluorescence properties of the involved compounds were studied using a JASCO FP6200 spectrofluorimeter.

\subsection{D Printing Experiments Upon Laser Diode or LED Projector}

3D printing experiments were carried out under air using a laser diode at $405 \mathrm{~nm}$ (spot size around $50 \mu \mathrm{m}$ ) or upon exposure to LED projector at $405 \mathrm{~nm}$, in the presence of new photosensitive cationic resins. A numerical optical microscopy (DSX-HRSU from OLYMPUS Corporation) was used in order to characterize the generated 3D patterns as reported by us in $[9,10]$.

\section{RESULTS AND DISCUSSION}

\subsection{Effect of Boron Compounds on the Absorption and Emission Spectra of a Coumarin}

The study of the absorption and fluorescence properties of the coumarin (Coum-b) with or without Borane or Borate was carried out in toluene (Figure 1). Taking into consideration the UVVisible absorption spectra, the addition of Borane to the solution containing the coumarin has a weak effect on the absorption spectra (Figure 1A: curve 2 or 3 vs. curve 1, respectively) while this effect is stronger when adding Borate to the coumarin solution (Figure 1B: curve 2 or 3 vs. curve 1 , respectively).

In contrast, a huge effect was observed in the fluorescence spectra when adding borane or borate i.e. the maximum fluorescence wavelength was about $440 \mathrm{~nm}$ for a solution of coumarin in toluene (curve 1 in Figures 2A and 2B) compared to $485 \mathrm{~nm}$ and $493 \mathrm{~nm}$ in the presence of $2 \times 10^{-}$

${ }^{3} \mathrm{M}$ and $5 \times 10^{-3} \mathrm{M}$ of Borane (or Borate), respectively (Figure 2A for Borane and Figure 2B for 
Borate). Actually, an approximately $45 \mathrm{~nm}$ bathochromic shift occurred in the presence of these boron compounds. This bathochromic effect is related to the formation of a complex between coumarin and Borane or Borate in the excited state. Therefore, boron compounds can complex the coumarins by changing considerably their emission spectra.

\section{Coumarin + Boron Compounds $\rightarrow$ Complex}
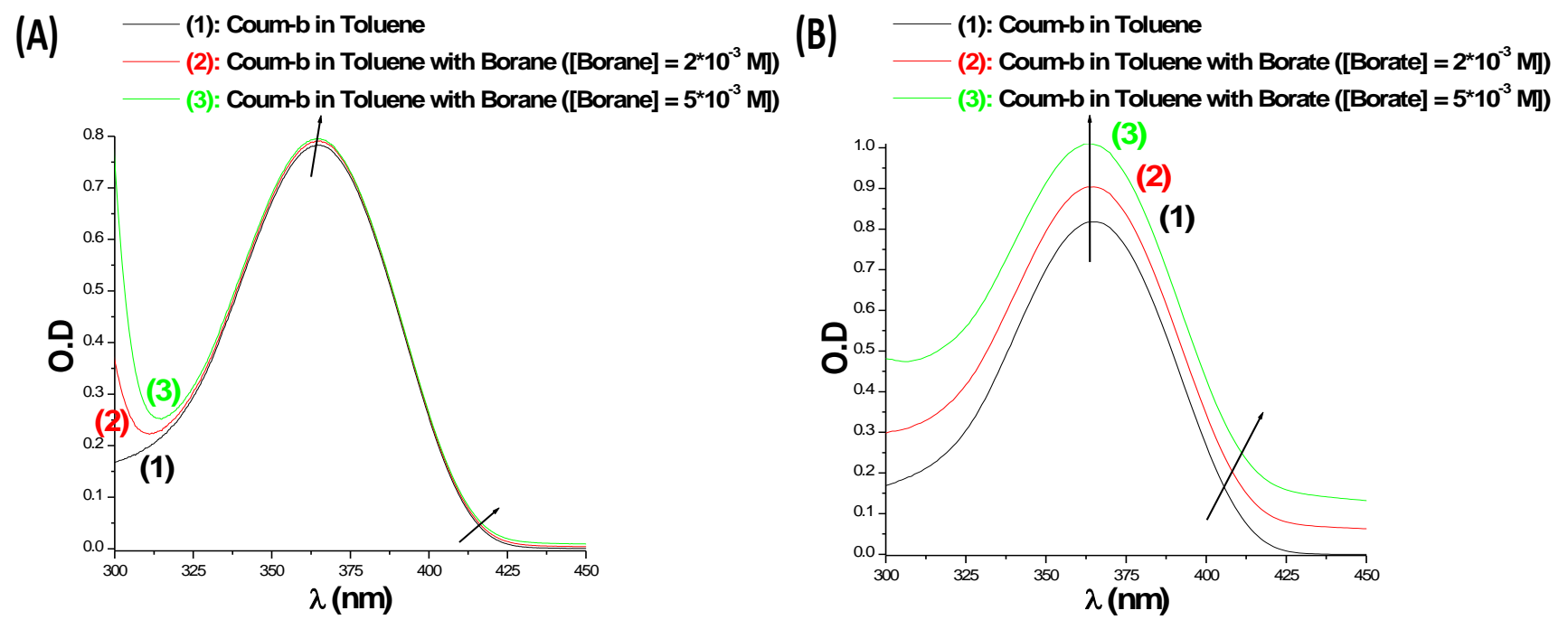

Figure 1. (A): Absorption spectra of Coumarin with or without Borane in Toluene; and (B): Absorption spectra of Coumarin with or without Borate in Toluene. 
(A)

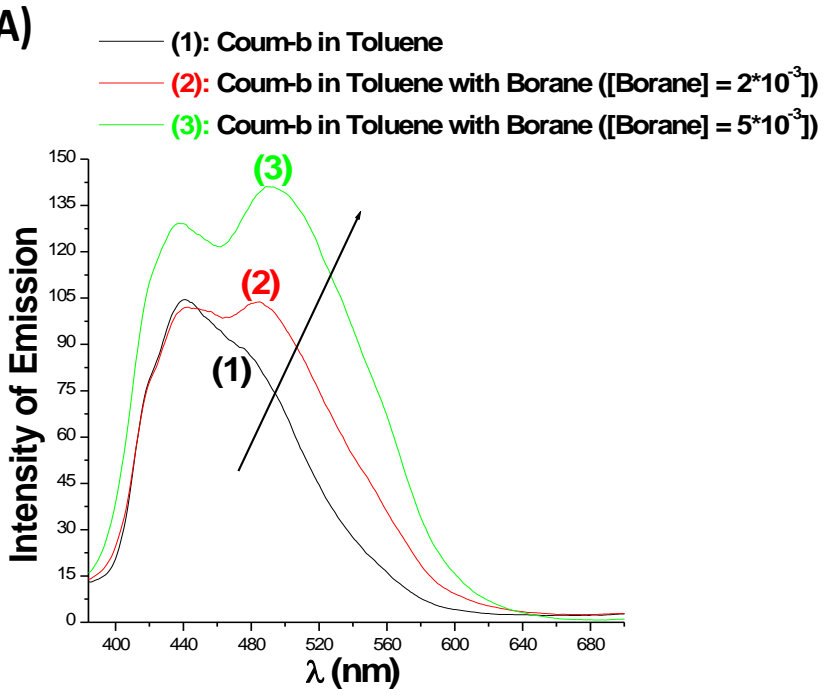

(B)

(1): Coum-b in Toluene

(2): Coum-b in Toluene with Borate ([Borate $\left.]=2^{*} 10^{-3}\right]$ )

(3): Coum-b in Toluene with Borate $\left([\right.$ Borate $\left.\left.]=5^{\star} 10^{-3}\right]\right)$

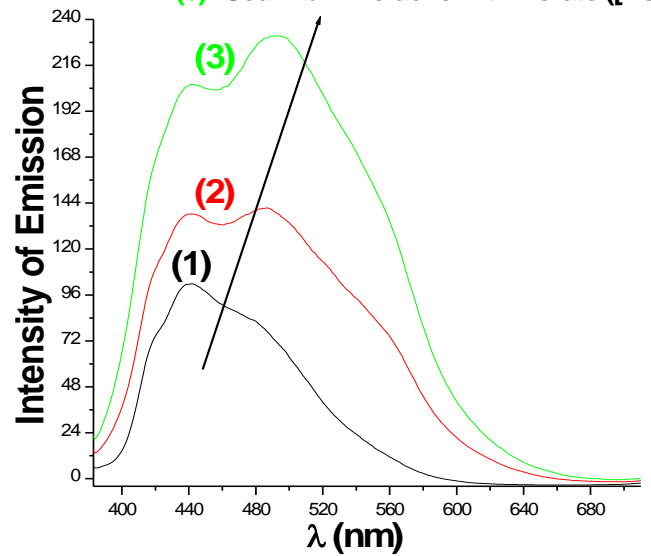

Figure 2. (A): Emission spectra of Coumarin for Different Borane Contents in Toluene $\left(\lambda_{\mathrm{ex}}=\right.$ $368.2 \mathrm{~nm})$; and (B): Emission spectra of Coumarin for Different Borate Contents in Toluene $\left(\lambda_{\mathrm{ex}}\right.$ $=368.2 \mathrm{~nm}$ ).

\subsection{Cationic Photopolymerization (CP) of Epoxy-silicones in the Presence of Boron}

\section{Compounds as Additives}

Actually, the $\mathrm{CP}$ of thin epoxide films $(25 \mu \mathrm{m})$ using epoxy-silicone as benchmarked monomer was performed under air, in the presence of the two-component Coum-a/SC939 $(0.05 \% / 1 \% \mathrm{w} / \mathrm{w})$ photoinitiating systems and the three-component Coum-a/SC939/Borane (or Borate) $(0.05 \% / 1 \% / 0.5 \%$ or $1 \%$ or $2 \% \mathrm{w} / \mathrm{w})$ PISs upon visible light irradiation with the LED at $405 \mathrm{~nm}$ (Figure 3). The final reactive epoxy function conversions (FC) are recapitulated in Table

1. Obviously, a clear increase in the performance of the system is noted in the presence of Borane as co-initiator for the $\mathrm{CP}$ of thin epoxy-silicone films where Coum-a/SC939/Borane $(0.05 \% / 1 \% / 0.5 \%$ or $1 \%$ or $2 \% \mathrm{w} / \mathrm{w})$ combinations lead to very high polymerization rates $(\mathrm{Rp})$ compared to the two-component Coum-a/SC939 (0.05\%/1\% w/w) system as shown in Figure 3A (curves 2 with $0.5 \%$ Borane, curve 3 with $1 \%$ Borane, curve 4 with $2 \%$ Borane vs. curve 1 without 
Borane). FC increases up to reach $40 \%$ with Coum-a/SC939/Borane $(0.05 \% / 1 \% / 0.5 \%$ w/w) after 75 s of irradiation compared to only $21 \%$ with the two-component Coum-a/SC939 $(0.05 \% / 1 \%$ w/w) system at this time of irradiation (curve 2 vs. curve 1 in Figure 3A, respectively).

The same enhancement was also observed when Borate was incorporated as a third component in Coum-a/SC939 system leading to a better efficiency with the three-component PISs compared to the two-component system for the $\mathrm{CP}$ of thin samples under the same irradiation conditions, where the performance of the system increases in terms of FC and Rp e.g. the maximum acrylate function conversion (FC) of epoxy group attained was about $41 \%$ with Couma/SC939/Borate $(0.05 \% / 1 \% / 0.5 \% \mathrm{w} / \mathrm{w})$ after $75 \mathrm{~s}$ of irradiation compared to only $21 \%$ with Couma/SC939 (0.05\%/1\% w/w) (curve 2 vs. curve 1 in Figure 3B, respectively; see also in Table 1). The same holds true when higher concentrations of Borate are used (curve 3 with 1\% Borate and curve 4 with $2 \%$ Borate vs. curve 1 without Borate, Table 1).

This behavior shows the big effect of boron compounds which can change both the fluorescence properties of coumarin and the reactivity of the system. This can be related to the complex ([Coum-B $]_{\text {Complex }}$ ) which forms once coumarin is combined with boron compounds. In addition, the $[\text { Coum-B }]_{\text {Complex }}$ can increase the reactivity of the coumarin with SC939 but also the reactivity of the radical cation, because this latter is complexed with Borane or Borate. Then, boron compounds are able to change the photochemistry, highlighting the big effect of boron compounds on the photonitiating ability of the system. In addition, all the obtained polymers are tack-free.

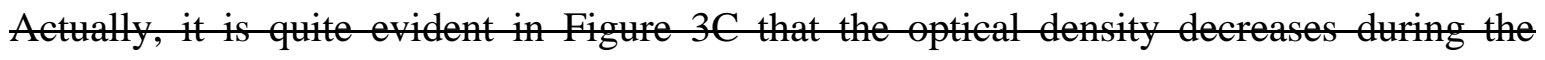
photpelymerization proving the formation of the polymer (the evolution of the epoxy group content of epoxy silicones was continuously followed at about $3000 \mathrm{~cm}^{-1}$ ). 
Otherwise, comparing Borane and Borate, both are quite efficient since both result in very high polymerization rates as shown in Figure 4. In fact, a small difference is observed in the final reactive epoxy function conversion (FC) where Borate results in slightly higher FCs compared to Borane, and this may be related to the better solubility of Borate.
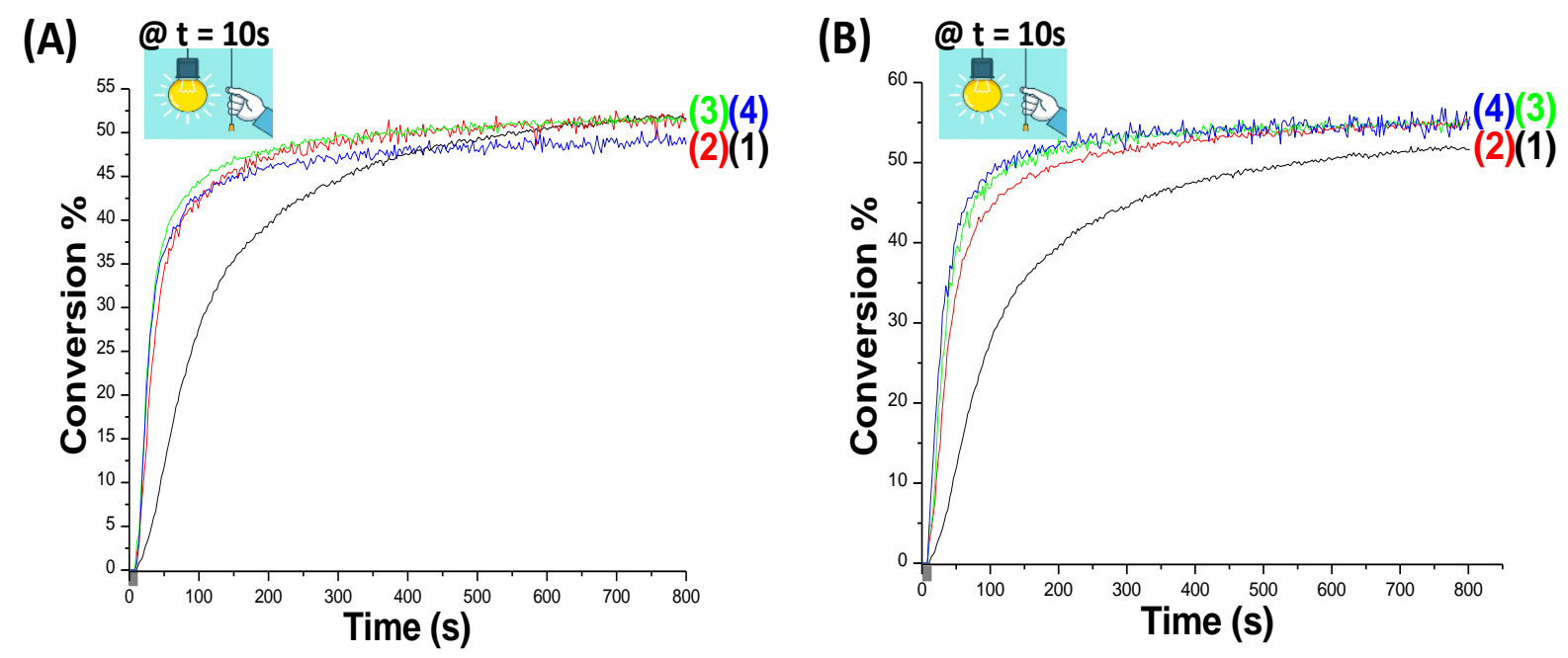

Figure 3. Polymerization profiles (epoxy function conversion vs. irradiation time) for thin epoxysilicone films (thickness $=25 \mu \mathrm{m}$ ) under air, upon irradiation with the LED@405 nm, using different two and three-component photoinitiating systems: (A): Without and With Borane: (1) Coum-a/SC939 (0.05\%/1\% w/w); (2) Coum-a/SC939/Borane (0.05\%/1\%/0.5\% w/w); (3) Couma/SC939/Borane $(0.05 \% / 1 \% / 1 \% \mathrm{w} / \mathrm{w})$; and (4) Coum-a/SC939/Borane $(0.05 \% / 1 \% / 2 \% \mathrm{w} / \mathrm{w})$, and (B): Without and With Borate: (1) Coum-a/SC939 (0.05\%/1\% w/w); (2) Coum-a/SC939/Borate $(0.05 \% / 1 \% / 0.5 \% \mathrm{w} / \mathrm{w})$; (3) Coum-a/SC939/Borate $(0.05 \% / 1 \% / 1 \% \mathrm{w} / \mathrm{w})$; and (4) Couma/SC939/Borate $(0.05 \% / 1 \% / 2 \% \mathrm{w} / \mathrm{w})$. The irradiation starts at $\mathrm{t}=10 \mathrm{~s}$. 


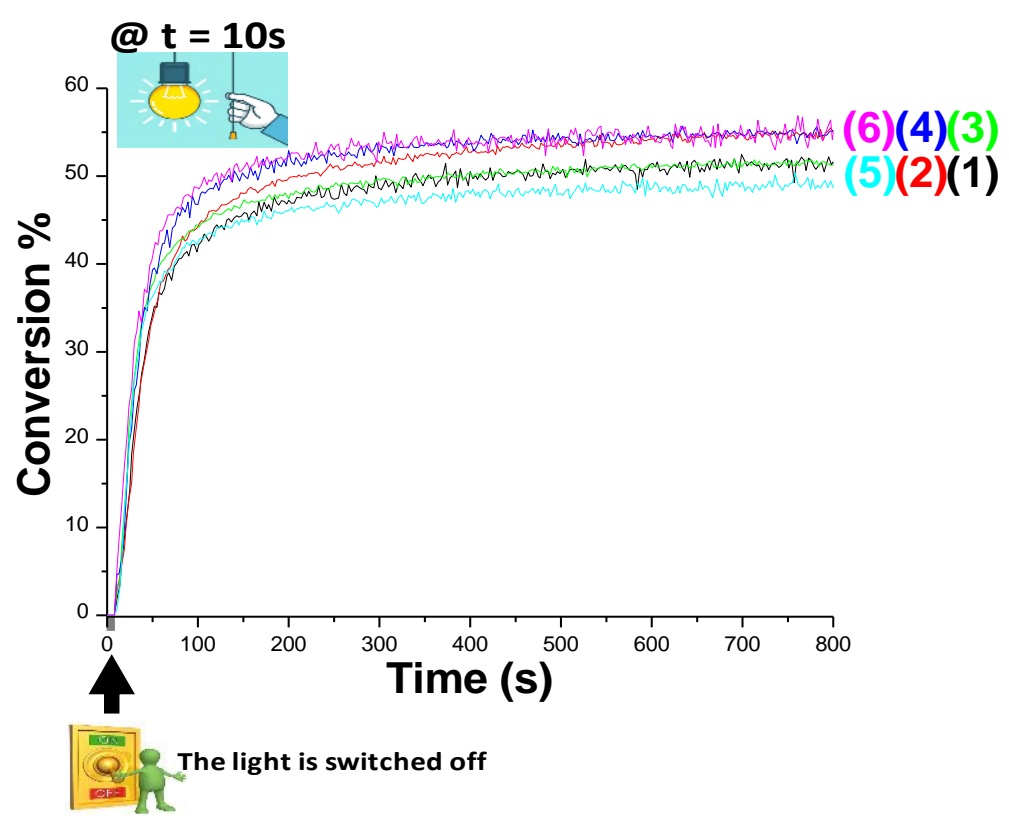

Figure 4. Comparison of polymerization profiles (epoxy function conversion vs. irradiation time) for epoxy-silicones in thin films $(25 \mu \mathrm{m}$, under air, LED at $405 \mathrm{~nm})$ between Borane and Borate: (1) Coum-a/SC939/Borane $(0.05 \% / 1 \% / 0.5 \% \mathrm{w} / \mathrm{w})$; (2) Coum-a/SC939/Borate $(0.05 \% / 1 \% / 0.5 \%$ w/w); (3) Coum-a/SC939/Borane $\quad(0.05 \% / 1 \% / 1 \%$ w/w); (4) Coum-a/SC939/Borate $(0.05 \% / 1 \% / 1 \% \mathrm{w} / \mathrm{w})$; (4) Coum-a/SC939/Borane $(0.05 \% / 1 \% / 2 \% \mathrm{w} / \mathrm{w})$; and (5) Coum$\mathrm{a} / \mathrm{SC} 939 /$ Borate $(0.05 \% / 1 \% / 2 \% \mathrm{w} / \mathrm{w})$; respectively.

Table 1. Final Reactive Epoxy Function Conversion (FC) for Epoxy-silicones using Different Two and Three-component PISs after 800s of Irradiation with the LED @ 405 nm.

\begin{tabular}{|c|c|c|}
\hline \multicolumn{3}{|c|}{ \% Epoxy Function Conversion (FC) (at $\mathrm{t}=\mathbf{8 0 0} \mathrm{s})$} \\
\hline \multicolumn{3}{|c|}{ (Thickness = 25 $\mu \mathrm{m}$ ) under air } \\
\hline Coum-a/SC939 & Coum-a/SC939/Borane & Coum-a/SC939/Borate \\
\hline $\mathbf{0 . 0 5 \% / 1 \% ~ w / w ) ~}$ & $52 \%^{\mathrm{a}}$ & $56 \%^{\mathrm{a}}$ \\
$52 \%$ & $5 \%^{\mathrm{b}}$ & $56 \%^{\mathrm{b}}$ \\
& $50 \%^{\mathrm{c}}$ & $56 \%^{\mathrm{c}}$ \\
\hline
\end{tabular}

a: Coum/SC939/Borane (or Borate): $(0.05 \% / 1 \% / 0.5 \% \mathrm{w} / \mathrm{w})$

b: Coum/SC939/Borane (or Borate): $(0.05 \% / 1 \% / 1 \% \mathrm{w} / \mathrm{w})$

c: Coum/SC939/Borane (or Borate): $(0.05 \% / 1 \% / 2 \% \mathrm{w} / \mathrm{w})$ 


\subsection{Effect of adding water on the Performance of the System for the Cationic Photopolymerization (CP) of Epoxy-silicones in the Presence of Boron Compounds as Co- initiators}

The effect of adding water to the system has been studied in the presence of the threecomponent Coum-a/SC939/Borane (or Borate) $(0.05 \% / 1 \% / 0.5 \%$ or $1 \%$ or $2 \%$ w/w) PISs for the $\mathrm{CP}$ of epoxides (using epoxy-silicone as standard monomer) in thin films $(25 \mu \mathrm{m})$ under air and upon irradiation with the LED at $405 \mathrm{~nm}$ (Figure 5).

As illustrated in Figure 5, the addition of 1\% water to the systems does not have a big effect on their performance where the polymerization profiles are almost the same with and without water (curves 3,5,7 vs. curves 2,4,6, respectively in Figure 5A with Borane and Figure 5B with Borate).

Generally, water has two classic effects in cationic polymerization: (i) An inhibiting effect which is that water reacts on the generated cations during the polymerization and inhibits the cationic polymerization, and this effect is mostly observed at high amounts of water, and (ii) The positive aspect of water is that water makes hydrogen bonds with the epoxy groups and therefore facilitates the opening of the cycle during the propagation stage, and this effect is observed at small quantities of water and known as "Activated monomer". In this case, water improves the performance of the system by increasing the conversion and then the reactivity.

Therefore, for $1 \%$ of water, we do not know if we are rather in an improvement or in an inhibition in the performance, what we observe is that we have basically little effect of water on the performance of the system and therefore we can have a little amount of water in our systems even up to $1 \%$. 

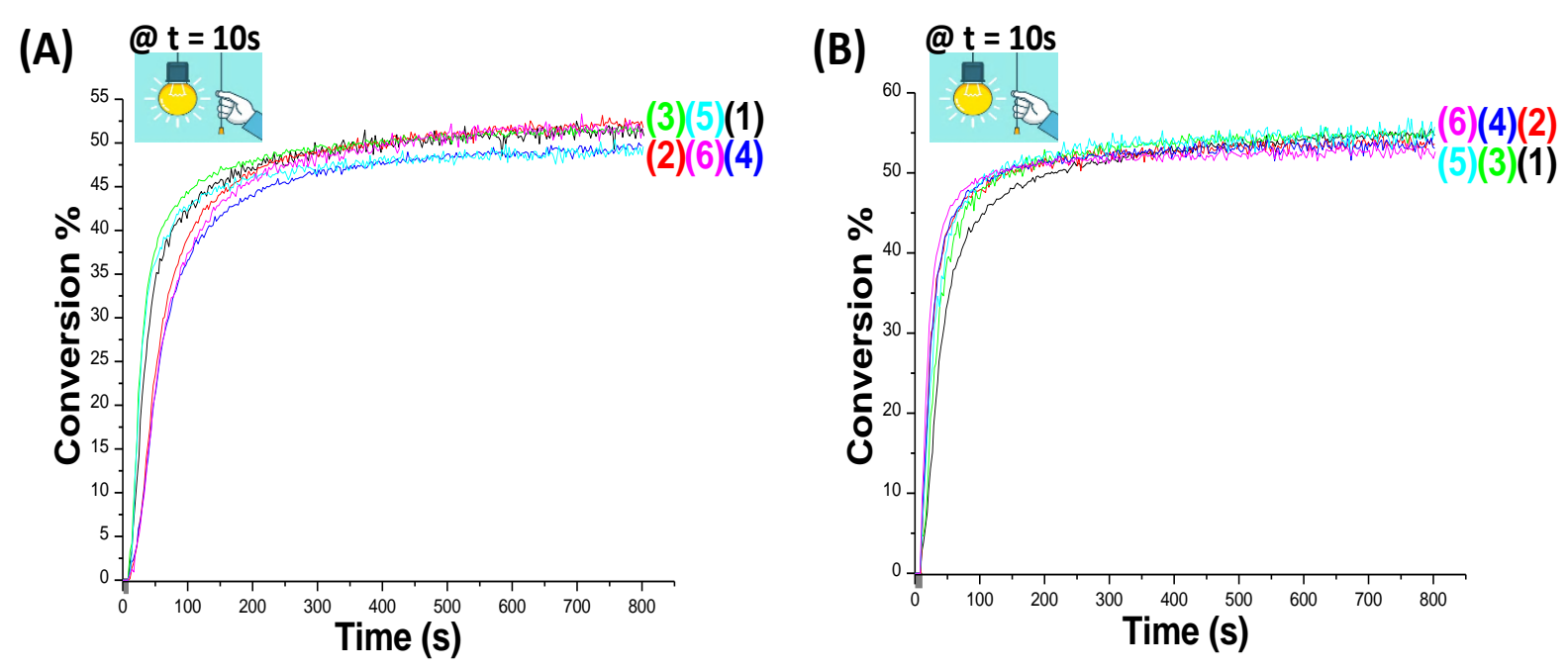

Figure 5. Effect of adding water on the polymerization profiles (epoxy function conversion vs. irradiation time) for thin epoxy-silicone films (thickness $=25 \mu \mathrm{m}$ ) under air, upon irradiation with the LED@405 nm, using different three and four-component photoinitiating systems: (A): With Borane: (1) Coum-a/SC939/Borane (0.05\%/1\%/0.5\% w/w); (2) Coum-a/SC939/Borane/ $\mathrm{H}_{2} \mathrm{O}$ (0.05\%/1\%/0.5\%/1\% w/w); (3) Coum-a/SC939/Borane $(0.05 \% / 1 \% / 1 \%$ w/w); (4) Couma/SC939/Borane/ $\mathrm{H}_{2} \mathrm{O}(0.05 \% / 1 \% / 1 \% / 1 \% \mathrm{w} / \mathrm{w}) ;(5)$ Coum-a/SC939/Borane $(0.05 \% / 1 \% / 2 \% \mathrm{w} / \mathrm{w})$; and (6) Coum-a/SC939/Borane/ $\mathrm{H}_{2} \mathrm{O}(0.05 \% / 1 \% / 2 \% / 1 \%$ w/w), and (B): With Borate: (1) Couma/SC939/Borate $\left(0.05 \% / 1 \% / 0.5 \%\right.$ w/w); (2) Coum-a/SC939/Borate/ $\mathrm{H}_{2} \mathrm{O}(0.05 \% / 1 \% / 0.5 \% / 1 \%$ w/w); (3) Coum-a/SC939/Borate $\left(0.05 \% / 1 \% / 1 \%\right.$ w/w); (4) Coum-a/SC939/Borate/ $\mathrm{H}_{2} \mathrm{O}$ $(0.05 \% / 1 \% / 1 \% / 1 \% \mathrm{w} / \mathrm{w})$; (5) Coum-a/SC939/Borate $(0.05 \% / 1 \% / 2 \% \mathrm{w} / \mathrm{w})$; and (6) Coum$\mathrm{a} / \mathrm{SC} 939 /$ Borate $/ \mathrm{H}_{2} \mathrm{O}(0.05 \% / 1 \% / 2 \% / 1 \% \mathrm{w} / \mathrm{w})$. The irradiation starts at $\mathrm{t}=10 \mathrm{~s}$.

\subsection{Dark Polymerization of Thin Epoxy-silicone Films in the Presence of Boron Compounds as Additives}

By definition, “Dark polymerization'” is a polymerization that continues without light. It is quite obvious that the polymerization was initiated when the irradiation was turned on (the irradiation starts at $\mathrm{t}=10 \mathrm{~s}$ ) and continues after switching off the irradiation (the irradiation was turned off at $t=30 \mathrm{~s}$ ) in the presence of the three-component Coum-a/SC939/Borane (or Borate) $(0.05 \% / 1 \% / 2 \%$ w/w) PISs (curve 2 with Borane and curve 4 with Borate in Figure 6). 
A slight decrease in the performance of the system is observed in the presence of Couma/SC939/Borane $(0.05 \% / 1 \% / 2 \% \mathrm{w} / \mathrm{w})$ system when the irradiation was turned off compared to when it was on for 800s (curve 2 vs. curve 1, respectively; Table 2). While, a slight increase in the system's performance is noted for Coum-a/SC939/Borate $(0.05 \% / 1 \% / 2 \%$ w/w) after turning off the light compared to when the light was continuously on for 800 s (curve 4 vs. curve 3 , respectively; Table 2).

Actually, in the case of cationic polymerization, the polymerization can continue without light because the created cations do not react with the oxygen and can therefore continue to react with epoxy groups which allows the cations to continue to propagate. Whereas, the oxygen inhibition which is clearly observed in radical polymerization prevents having a dark polymerization.

Besides, the presence of water or impurities or nucleophilic groups in the medium (which can react on the created cations) prevent dark polymerization in the case of $\mathrm{CP}$.
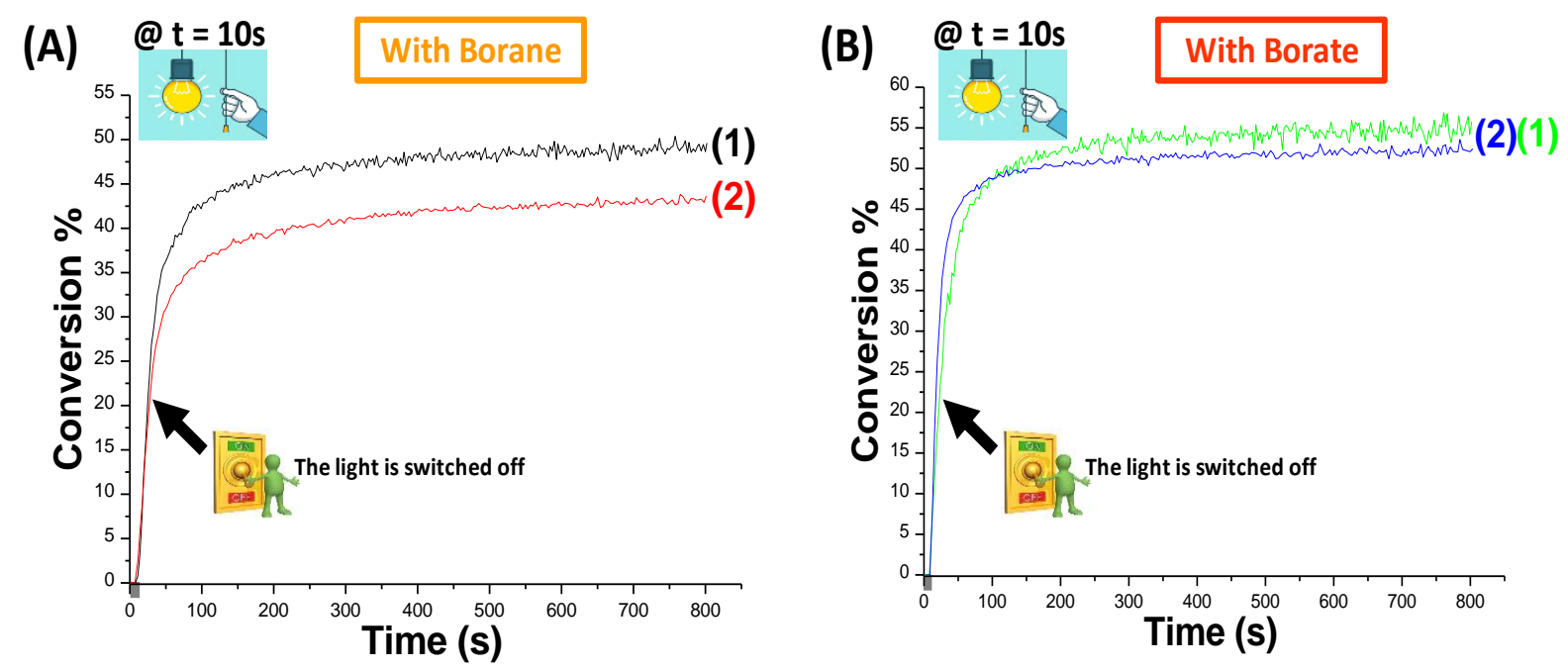

Figure 6. Polymerization profiles (epoxy function conversion vs. irradiation time) for thin epoxysilicone films (thickness $=25 \mu \mathrm{m}$ ) under air, upon irradiation with the LED@405 nm, using 
different three-component photoinitiating systems: (A): (1) Coum-a/SC939/Borane $(0.05 \% / 1 \% / 2 \% \mathrm{w} / \mathrm{w})$ (when the light was continuously on for 800s); (2) Coum-a/SC939/Borane $(0.05 \% / 1 \% / 2 \% \mathrm{w} / \mathrm{w})$ (when the irradiation was turned off at $\mathbf{t}=30 \mathrm{~s})$. (B): (1) Couma/SC939/Borate $(0.05 \% / 1 \% / 2 \% \mathrm{w} / \mathrm{w})$ (when the light was continuously on for 800s); (2) Couma/SC939/Borate $(0.05 \% / 1 \% / 2 \% \mathrm{w} / \mathrm{w})$ (when the irradiation was turned off at $\mathbf{t}=\mathbf{3 0 s}$ ). The irradiation starts at $\mathrm{t}=10 \mathrm{~s}$.

Table 2. Final Reactive Epoxy Function Conversion (FC) for Epoxy-silicones using Different Three-component PISs upon irradiation with the LED @405 nm.

\begin{tabular}{|c|c|}
\hline \multicolumn{2}{|c|}{$\%$ Epoxy Function Conversion (FC) } \\
\hline \multicolumn{2}{|c|}{ (Thickness = 25 $\mu \mathrm{m}$ ) under air } \\
\hline Coum-a/SC939/Borane & Coum-a/SC939/Borate \\
\hline $50 \%^{\mathrm{a}}$ & $56 \%^{\mathrm{a}}$ \\
$44 \%^{\mathrm{b}}$ & $53 \%^{\mathrm{b}}$ \\
\hline
\end{tabular}

a: When the light was continuously on for $800 \mathrm{~s}$

$\mathrm{b}$ : When the irradiation was turned off at $\mathrm{t}=30$ s (Dark Polymerization)

\subsection{Cationic Photopolymerization (CP) of (3,4-Epoxycyclohexane)methyl 3,4-} epoxycyclohexylcarboxylate in the Presence of Boron Compounds as Additives

The effect of boron compounds on the performance of the system has been also studied for the cationic polymerization of epoxides using EPOX as the benchmarked monomer for thin samples (25 $\mu \mathrm{m}$, under air) upon irradiation with the LED at $405 \mathrm{~nm}$ (Figure 7). Evidently, the CP in the presence of Coum-b/SC938/Borane (or Borate) $(0.5 \% / 1 \% / 0.5 \%$ w/w) PISs lead to a higher efficiency in terms of final epoxy function conversions (FCs) and also rates of polymerization (Rp) compared to the two-component PIS based on Coum-b/SC938 (0.5\%/1\% w/w) couple (curve 2 with Borane and curve 3 with Borate vs. curve 1, respectively; see also in Table 3).

This behavior calls attention to the effect of boron compounds on the reactivity of the system which is related to the formed complex between coumarin and boron compounds, highlighting again the immense role of boron compounds on the global performance of the system. 
Otherwise, a new peak assigned to the formation of the polyether network appears at $\sim 1080$ $\mathrm{cm}^{-1}$ during the photopolymerization process (see the FTIR spectra in the $700-1150 \mathrm{~cm}^{-1}$ range in Figure 7B for Coum-b/SC938/Borate $(0.5 \% / 1 \% / 0.5 \% \mathrm{w} / \mathrm{w}))$. Note that the obtained polymers are a little bit tacky at the surface.
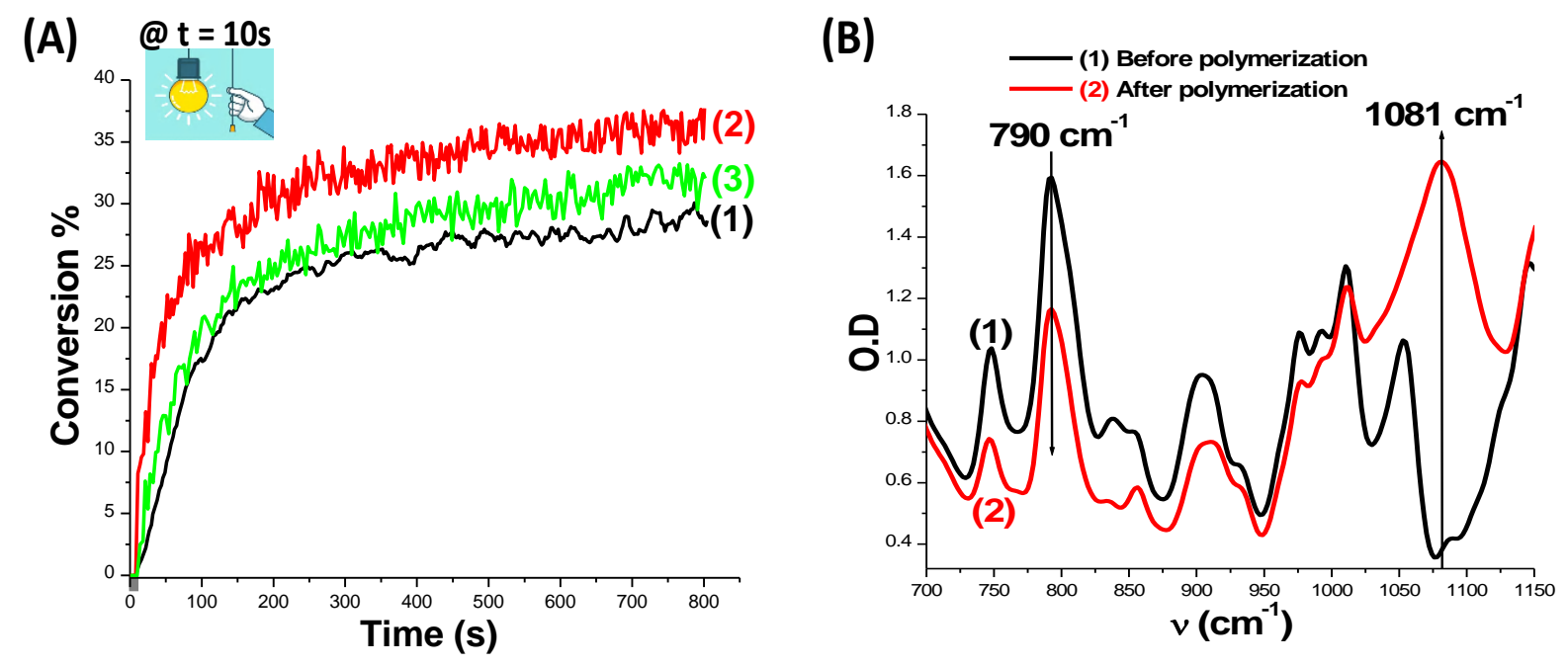

Figure 7. (A): Polymerization profiles (epoxy function conversion vs. irradiation time) for EPOX in thin films $(25 \mu \mathrm{m})$ under air, upon irradiation with the LED@ $405 \mathrm{~nm}$, using different two and three-component photoinitiating systems: (1) Coum-b/SC938 (0.5\%/1\% w/w); (2) Coumb/SC938/Borane (0.5\%/1\%/0.5\% w/w); and (3) Coum-b/SC938/Borate $(0.5 \% / 1 \% / 0.5 \%$ w/w). The irradiation starts at $\mathrm{t}=10 \mathrm{~s}$. (B): IR spectra registered before and after polymerization for Coumb/SC938/Borate $(0.5 \% / 1 \% / 0.5 \%$ w/w) upon exposure to the LED @ 405 nm.

Table 3. Final Reactive Epoxy Function Conversion (FC) for EPOX in the Presence of Different Two $(0.5 \% / 1 \% \mathrm{w} / \mathrm{w})$ and Three-component $(0.5 \% / 1 \% / 0.5 \% \mathrm{w} / \mathrm{w})$ PISs after $800 \mathrm{~s}$ of Irradiation with the LED @405 nm.

\begin{tabular}{|c|c|c|}
\hline \multicolumn{3}{|c|}{ \% Epoxy Function Conversion (FC) (at $\mathrm{t}=800 \mathrm{~s}$ ) } \\
\hline \multicolumn{3}{|c|}{ (Thickness = 25 $\mu \mathrm{m}$ ) under air } \\
\hline Coum-b/SC938 & Coum-b/SC938/Borane & Coum-b/SC938/Borate \\
\hline $29 \%$ & $38 \%$ & $33 \%$ \\
\hline
\end{tabular}




\subsection{D Printing Experiments Upon LED Projector and by means of Laser Diode for the}

\section{Access to 3D Generated Patterns using Coum-a/SC939/Borate System}

Very high efficiency was observed in the presence of Coum-a/SC939/Borate PISs which allows their use for 3D printing applications through a cationic process. This latter is able to reduce the shrinkage usually observed in radical polymerization for 3D printing experiments. The laser write experiments were successfully performed under air by means of a laser diode at $405 \mathrm{~nm}$ using epoxy silicone as organic resin in order to generate thick 3D samples. The generated samples were obtained in a very short time of irradiation $(<1 \mathrm{~min})$ and with a very high spatial resolution (only limited by the size of the laser diode beam: spot of $50 \mu \mathrm{m}$ ). Otherwise, some $3 \mathrm{D}$ printing experiments were carried out upon exposure to a LED projector at $405 \mathrm{~nm}$ having a quite low light intensity (see the experimental part), where the thin 3D patterns are generated under air during only 10 s of irradiation. Indeed, the thin $3 D$ patterns are obtained by projection of an entire layer at one time for each layer. Finally, the generated thick 3D patterns were characterized by a numerical optical microscopy and the results are presented in Figure 8.

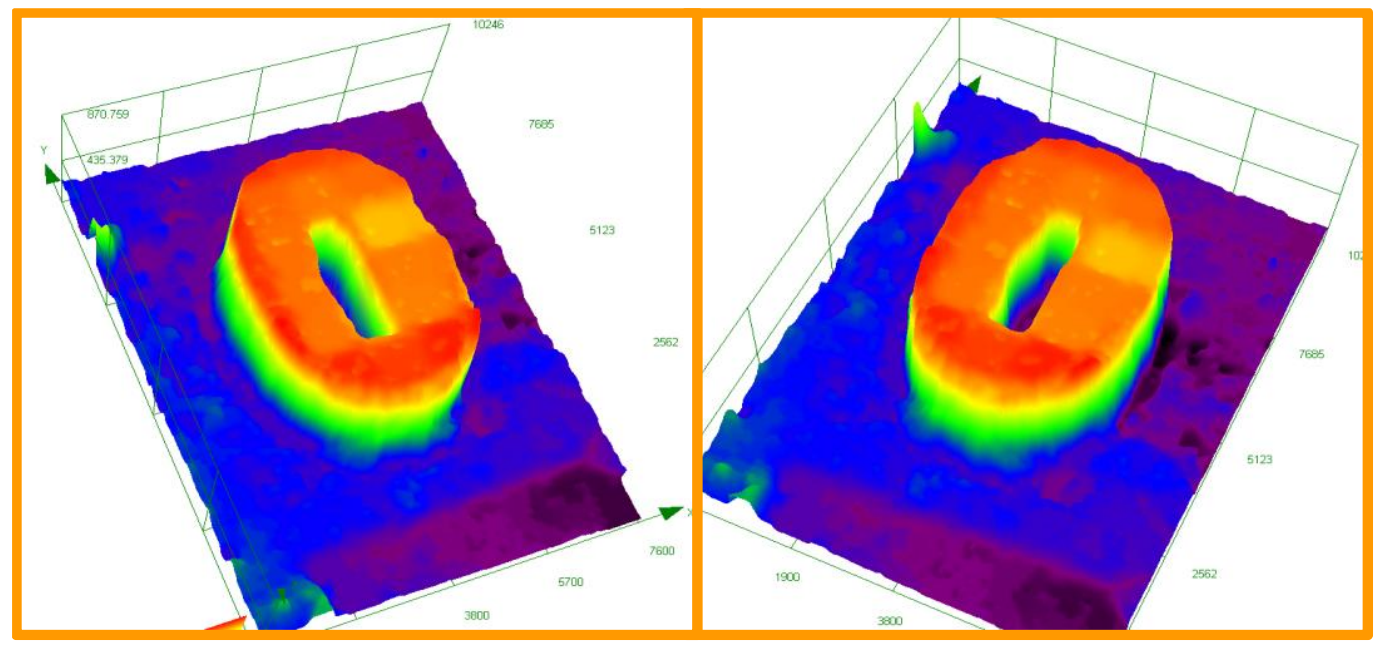

Figure 8. 3D Printing experiments upon Laser Diode (@405 nm) or LED projector (@405 nm) for CP: Characterization of the thick and thin 3D written patterns by a numerical optical 
microscopy: Coum-a/SC939/Borate $(0.05 \% / 1 \% / 2 \%$ w/w) in epoxy-silicones upon laser diode (thickness $=960 \mu \mathrm{m}$ ).

\subsection{Chemical Mechanisms}

A global proposed photochemical mechanism is proposed and given in Scheme 3 (reactions r1-r4) in order to better understand the interactions that take place. Actually, the interaction between coumarin and iodonium salt (SC939 or SC938) occurs through a photo-oxidation process [11].

Otherwise, the combination of coumarin and boron compounds (B) results in the formation of a complex ([Coum-B $\left.]_{\text {Complex }}\right)$ which increases the reactivity of the system (r3). In the case of the three-component Coum/Iod/Borane (or Borate) systems, [Coumarin-B] ${ }^{\bullet+}$ can be considered as initiating species for the $\mathrm{CP}(\mathrm{r} 4)$.

Finally, for the four-component systems Coum/Iod/Borane (or Borate) $/ \mathrm{H}_{2} \mathrm{O}, \mathrm{H}_{3} \mathrm{O}^{+----}$ $[\mathrm{BOH}]^{-}$can be also considered as initiating species for the $\mathrm{CP}$ as published in other previously studies [2].

Thus, Coumarin $^{\bullet+}$ (for the two-component PISs), [Coumarin-B $]^{\bullet+}$ (for the three and fourcomponent PISs) and $\mathrm{H}_{3} \mathrm{O}^{+}----[\mathrm{BOH}]^{-}$(for the four-component PISs) can be considered as the initiating species for the $\mathrm{CP}$. Alternatively, in the presence of radical cations, the release of intiating Brønsted acid for CP [12] can be also observed.

Coumarin $\rightarrow{ }^{*}$ Coumarin $\quad(h v)$

${ }^{*}$ Coumarin $+\mathrm{Ar}_{2} \mathrm{I}^{+} \rightarrow$ Coumarin $^{\bullet+}+\mathrm{Ar}_{2} \mathrm{I}^{\bullet}$

$\mathrm{Ar}_{2} \mathrm{I}^{\bullet} \rightarrow \mathrm{Ar}^{\bullet}+\mathrm{ArI}$

Coumarin $+\mathrm{B} \rightarrow[\text { Coumarin-B }]_{\text {Complex }}$ 
$[\text { Coumarin-B }]_{\text {Complex }}+\mathrm{Ar}_{2} \mathrm{I}^{+} \rightarrow[\text { Coumarin-B }]^{\bullet+}+\mathrm{Ar}^{\bullet}+\mathrm{ArI}$

Scheme 3. Proposed Photochemical Mechanisms for Photopolymerization Processes Initiated by Coumarins and Co-initiated by Boron Compounds.

Besides, borane can complex the epoxy monomer in order to activate the $\mathrm{CP}$ process and borate can stabilize the cationic species with a low nucleophilicity increasing the performance of the $\mathrm{CP}$ process.

\section{Conclusion}

In summary, boron componds having batho and hyperchromic effect on the emission spectra of a coumarin are able to push the cationic polymerization (CP) of epoxides (epoxy-silicone or EPOX) in the presence of iodonium salts (SC939 or SC938) as additives upon irradiation with the LED at $405 \mathrm{~nm}$. The big effect of boron compounds is related to the complex which is formed between coumarin and Borane or Borate resulting in an increase in the performance of the system in terms of rates of polymerization but also final reactive function conversions, and thus an increase in the reactivity of the system and a change in the photochemistry. Otherwise, the effect of adding water on the reactivity of the systems has been studied. In addition, the investigated photoinitiating systems (Coum-a/S939/Borane (or Borate)) are very efficient for “'Dark Polymerization”. Boron compounds were successfully used for the development of new cationic resins for 3D printing using LED projector at $405 \mathrm{~nm}$ but also for laser writing experiments upon laser diode (@ $405 \mathrm{~nm}$ ). The development of new high-performance co-initiators are being prepared and will be presented in our forthcoming papers. 


\section{Acknowledgments:}

The Lebanese group would like to thank "The Association of Specialization and Scientific Guidance" (Beirut, Lebanon) for funding and supporting this scientific work. 


\section{REFERENCES:}

[1] Mori T.; Yoshigoe Y.; Kuninobu Y. Control of Multicolor and White Emission by Adjusting the Equilibrium between Fluorophores, Lewis Acids, and Their Complexes in Polymers. Angew. Chem. Int. Ed. 2019, 58, 14457-14461.

[2] Kostjuk S. V. Controlled cationic polymerization of p-methoxystyrene co-initiated by $\mathrm{B}\left(\mathrm{C}_{6} \mathrm{~F}_{5}\right)_{3}$ : effect of electron donor and proton trap. 2020, under press.

[3] Mironov V.; Boland T.; Trusk T.; Forgacs G.; Markwald R.R. Organ Printing: computer-aided jet-based 3D tissue engineering. Biotechnol. J. 2003, 21, 157-161.

[4] Ballard D. H.; Trace A. P.; Ali S.; Hodgdon T.; Zygmont M. E.; DeBenedectis C. M.; Smith S. E.; Richardson M. L.; Patel M. J.; Decker S. J.; Lenchik L. Clinical Applications of 3D Printing: Primer for Radiologists, 2018, 25, 52-65.

[5] Liu Z.; Zhang M.; Bhandari B.; Wang Y. 3D printing: Printing precision and application in food sector, 2017, 69, 83-94.

[6] Dietlin C.; Schweizer S.; Xiao P.; Zhang J.; Morlet-Savary F.; Graff B.; Fouassier J.P.; Lalevée J. Photopolymerization upon LEDs: new photoinitiating systems and strategies. Polym. Chem. 2015, 6, 3895-3912.

[7] Lalevée J.; Blanchard N.; Tehfe M. A.; Morlet-Savary F.; Fouassier J.P. Green Bulb Light Source Induced Epoxy Cationic Polymerization under Air Using Tris(2,2'bipyridine)ruthenium(II) and Silyl Radicals. Macromolecules 2010, 43, 10191-10195.

[8] Lalevée J.; Blanchard N.; Tehfe M. A.; Peter M.; Morlet-Savary F.; Gigmes D.; Fouassier J.P. Efficient Dual Radical/Cationic Photoinitiator under Visible Light: A New Concept. Polym. Chem. 2011, 2, 1986-1991. 
[9] Zhang J.; Dumur F.; Xiao P.; Graff B.; Bardelang D.; Gigmes D.; Fouassier J.P.; Lalevée J. Structure Design of Naphthalimide Derivatives: Toward Versatile Photoinitiators for NearUV/Visible LEDs, 3D Printing, and Water-Soluble Photoinitiating Systems. Macromolecules. 2015, 48, 2054-2063.

[10] Xiao P.; Dumur F.; Zhang J.; Fouassier J.P.; Gigmes D.; Lalevée J. Copper Complexes in Radical Photoinitiating Systems: Applications to Free Radical and Cationic Polymerization upon Visible LEDs. Macromolecules. 2014, 47, 3837-3844.

[11] Zivic N.; Bouzrati-Zerelli M.; Kermagoret A.; Dumur F.; Fouassier J.P.; Gigmes D.; Lalevée J. Photocatalysts in Polymerization Reactions. ChemCatChem 2016, 8, 1617-1631.

[12] Budreckiene R.; Lazauskaite R.; Buika G.; Grazulevicius J.V. Cationic photopolymerization of carbazolyl-containing vinyl ethers. J. Photochem. and Photobio. A Chem. 2003, 157, 117-123. 


\section{TOC graphic:}

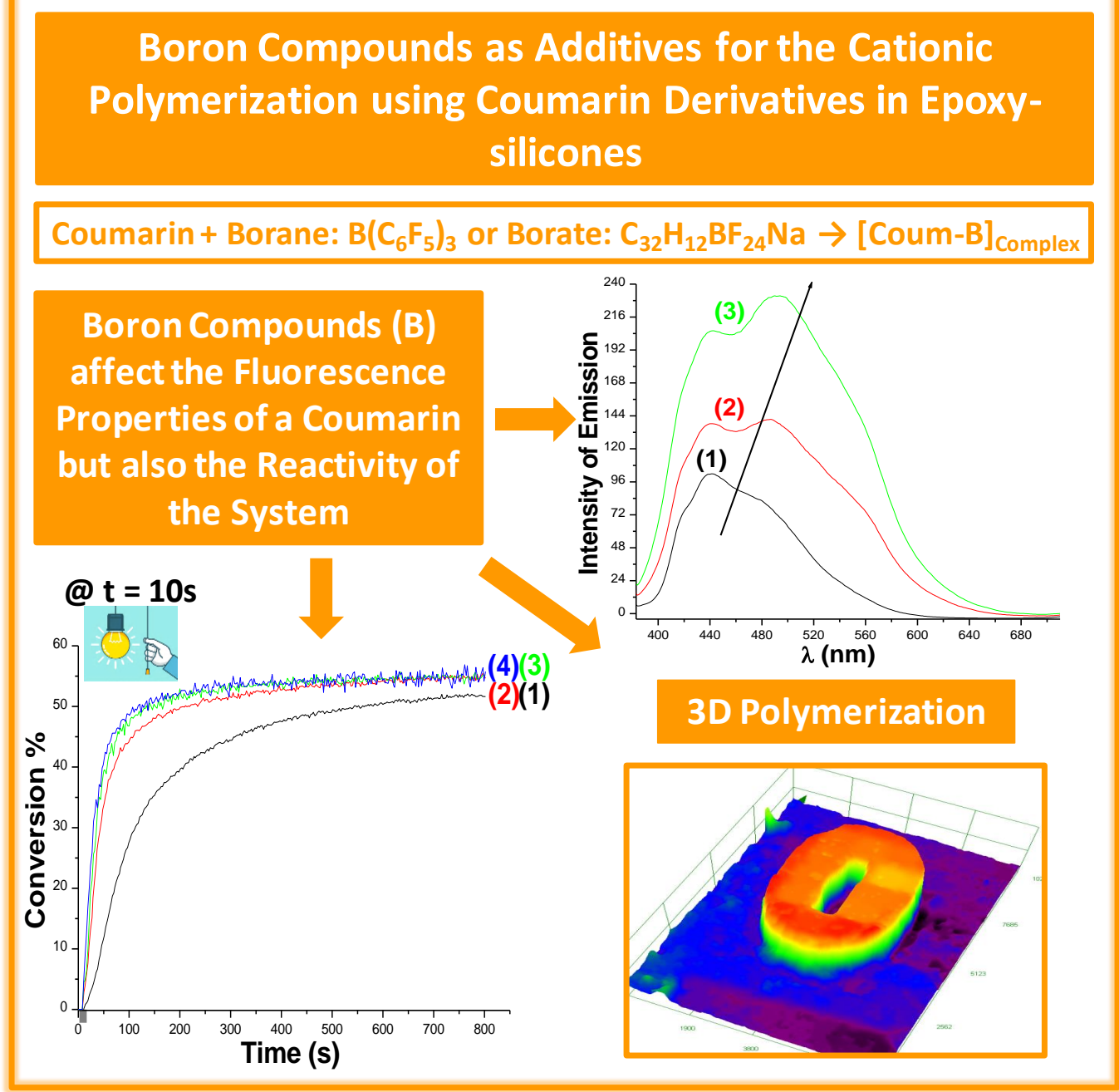

